\title{
EVALUASI EKOLOGIS SUAKA PERIKANAN DANAU BATU BUMBUN DI DAERAH ALIRAN SUNGAI MAHAKAM TENGAH DAN IMPLIKASI PENGELOLAANNYA
}

\author{
Endi Setiadi Kartamihardja*) dan Hendra Satria*
}

\begin{abstract}
ABSTRAK
Penetapan sebagian wilayah perairan umum sebagai suaka perikanan yang berfungsi sebagai habitat bagi komunitas ikan berperanan penting dalam melanjutkan daur hidupnya sehingga dari habitat tersebut akan dipasok benih maupun induk ikan. Penelitian ini bertujuan untuk mengevaluasi peranan suaka perikanan Danau Batu Bumbun di Daerah Aliran Sungai (DAS) Mahakam Tengah, Kalimantan Timur. Metode survai secara strata untuk mengetahui aspek ekologi perairan dan populasi ikannya dilakukan pada bulan Agustus dan November 1994, Januari, Maret, Juni, dan Nopember 1995, dan Maret 1996. Distribusi dan pola migrasi ikan di sekitar suaka dipelajari dengan penandaan (tagging) ikan yang dominan yaitu ikan pepuyu (Anabas testudineus), biawan (Helostoma temminckii), baung (Mystus nemurus), sepat siam (Trichogaster pectoralis), dan puyau (Osteochilus hasselti). Berdasarkan aspek ekologi perairan dan populasi ikannya, suaka Danau Batu Bumbun termasuk suaka yang berperanan cukup efektif sebagai suaka untuk jenis-jenis ikan rawa. Untuk meningkatkan peranan dan efektivitas suaka tersebut perlu dilakukan perbaikan pengelolaannya dengan melibatkan partisipasi masyarakat nelayan setempat. Aspek teknik pengelolaan yang perlu dilakukan meliputi: pengelolaan habitat, pengelolaan populasi ikan, pengembangan pengawasan, dan peraturan secara aktif dan pengembangan kelembagaan serta sosialisasi suaka.
\end{abstract}

\section{ABSTRACT: Ecological evaluation on fisheries reserve of lake Batu Bumbun at Middle Mahakam river basin, and its management implication. By : Endi Setiadi Kartamihardja and Hendra Satria}

The establishment of fisheries reserve as a habitat for fish community to sustain of their life cycle has an important role in producing the fish fry as well as the brood stock. A study to evaluate the effectiveness of fisheries reserve and to improve its management pattern has been done at Lake Batu Bumbun. Middle Mahakam river basin, East Kalimantan. Aquatic ecology, fish biology and fisheries of the reserve were studied using a stratified sampling method at August and November 1994, January, March, June, November 1995, and March 1996. Migration pattern of the dominant fish species namely pepuyu (Anabas testudineus), biawan (Helostoma temmincki), baung (Mystus nemurus), sepat siam (Trichogaster pectoralis), and puyau (Osteochilus hasselti) were studied using a tagging method. Based on the aquatic ecological and fish population characteristics, lake Batu Bumbun was sufficiently effective as a black fish reserve. A communitybased management was recommended as a management tool to increase the effectiveness of the reserve. Technical management aspects should include management of habitat, management of fish population, development of law enforcement, regulation and institution, and socialization of the reserve.

KEYWORDS: aquatic ecology, fish population, reserve, river basin, lake, fisheries management

\section{PENDAHULUAN}

Di perairan umum Kalimantan hidup tidak kurang dari 500 jenis ikan yang sebagian besar termasuk ke dalam ordo Ostariophysi dan Labyrinthici (Kottelat et al., 1993), sedangkan di perairan Mahakam Tengah, Kalimantan Timur tercatat sejumlah 147 jenis ikan yang temasuk kedalam 35 famili dan didominasi oleh famili Cyprinidae (Christensen, 1992). Dewasa ini, di perairan Mahakam Tengah terutama di Danau Semayang dan Melintang, beberapa jenis ikan sudah semakin sulit didapat dan hasil tangkapan nelayanpun mengalami penurunan (Anonim, 1991). Padahal wilayah Mahakam Tengah sangat terkenal sebagai sentra produksi ikan, karena hasil tangkapan ikan air tawarnya yang terbesar di Indonesia. Hasil tangkapan nelayan yang menurun tersebut antara lain disebabkan oleh adanya intensitas penangkapan dan penggunaan alat tangkap yang merusak, pendangkalan dan musim kemarau yang panjang (Purnomo, 1993). 


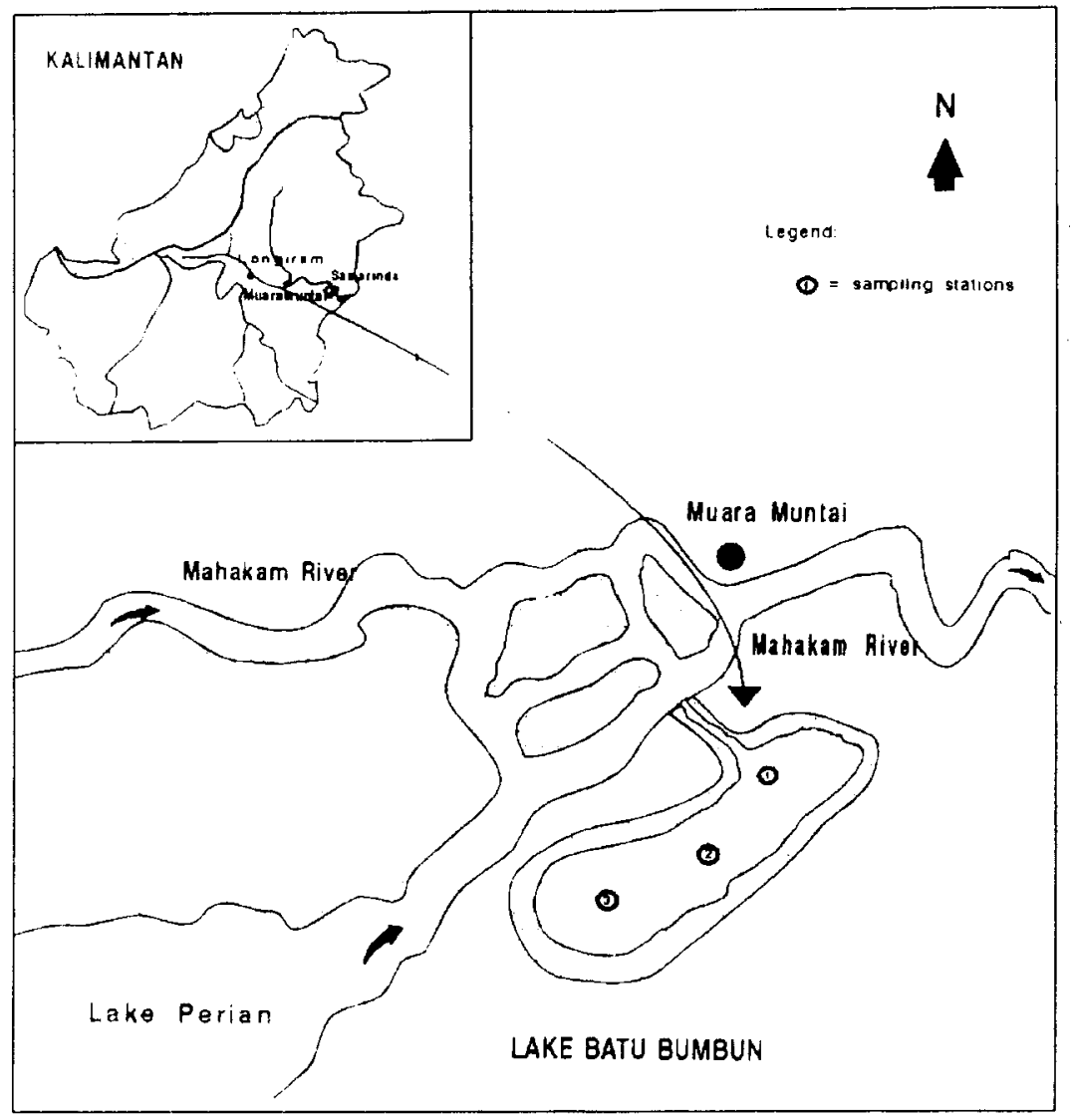

Gambar 1. Peta suaka Danau Batu Bumbun dengan statiun penelitiannya Figure 1. Map of Batu Bumbun reserve showing three sampling stations

Salah satu upaya yang dapat dilakukan untuk mengurangi penurunan sumber daya ikan tersebut adalah membentuk suaka perikanan. Suaka perikanan akan berfungsi sebagai habitat bagi komunitas ikan dalam melanjutkan daur hidupnya sehingga dari habitat tersebut dipasok benih untuk menggantikan ataupun menambah peremajaan (recruitment) stok ikan. Suaka perikanan juga berfungsi sebagai penyediaan induk ikan. Dengan demikian, suaka perikanan yang berfungsi baik dan efektif serta diikuti dengan pengelolaan yang tepat diharapkan akan berperanan positif dalam peningkatan produksi benih secara alami. Pada akhirnya, suaka yang efektif akan berpengaruh terhadap peningkatan produksi, pelestarian sumber daya dan kekayaan plasma nutfah ikan serta peningkatan dan pelestarian hasil tangkapan nelayan.

Di daerah aliran sungai (DAS) Mahakam Tengah terdapat beberapa suaka perikanan, seperti Danau Batu Bumbun (450 ha), Jantur Malang (75 ha), Loakang (750 ha), Danau Gab (150 ha), dan Danau Sirom (750 ha). Jumlah suaka perikanan ini masih belum memadai begitu pula cara pengelolaannya. Hal ini dicirikan antara lain oleh padatnya populasi gulma air, tidak terdapatnya atau rusaknya saluran peng- hubung antara suaka dengan daerah penangkapan, populasi ikan menunjukkan gejala tangkap lebih (overfishing), larangan penangkapan yang kurang dipatuhi dan pendangkalan (Sarnita, 1994).

Mengingat hal-hal tersebut di atas, maka evaluasi akan fungsi dan efektivitas suaka perikanan serta upaya perbaikan pengelolaannya untuk menjamin kelestarian sumber daya ikan perlu dilakukan. Untuk itu, aspek-aspek ekologi perairan, populasi ikan dan status pengelolaannya perlu diketahui. Penelitian ini bertujuan untuk mengevaluasi fungsi dan efektivitas suaka perikanan Danau Batu Bumbun, melalui studi aspek ekologi perairan dan populasi ikan serta upaya perbaikan pola pengelolaannya.

\section{BAHAN DAN METODE}

\section{Lokasi dan Waktu Penelitian}

Lokasi penelitian yang dipilih adalah salah satu suaka perikanan yakni suaka Danau Batu Bumbun, di Kecamatan Muara Muntai, DAS Mahakam Tengah, Kalimantan Timur (Gambar 1). Sampling dilakukan sebanyak tujuh kali yakni pada bulan Agustus dan November 1994, Januari, Maret, Juni, dan November 1995, dan Maret 1996. Waktu tersebut mewakili 

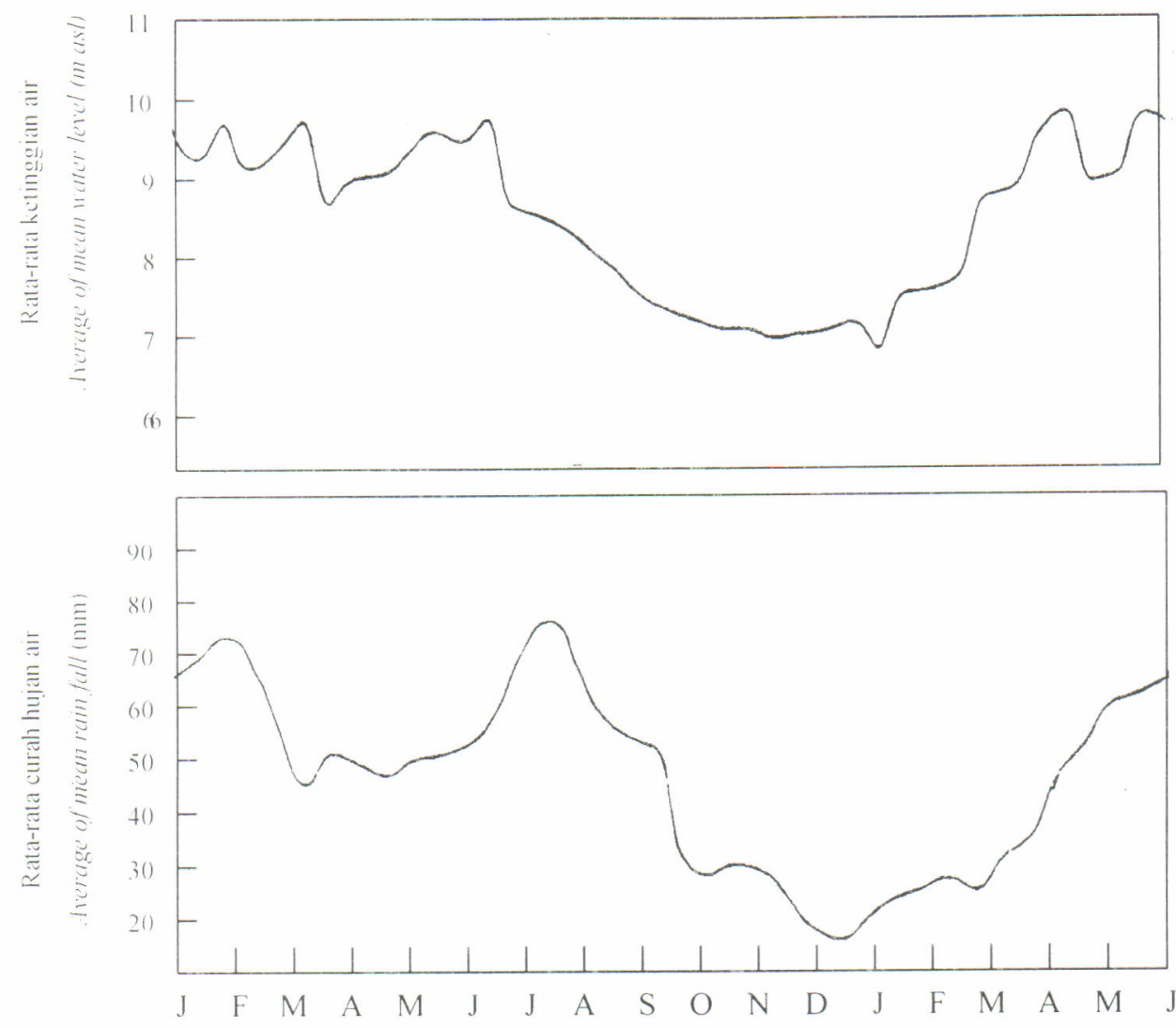

Gambar 2. Rata-rata fluktuasi ketinggian air dan curah hujan di DAS Mahakam Tengah tahun 1983-1993 Figure 2. Mean water level fluctuation and rainfall of the Middle Mahakam river basins in 1983-1993

peralihan musim hujan ke kemarau (Juni), kemarau (Agustus), peralihan kemarau ke hujan (November) dan musim hujan (Januari dan Maret) sesuai dengan ratarata curah hujan dan fluktuasi ketinggian air di DAS Mahakam Tengah seperti tertera pada Gambar 2.

\section{Penelitian Ekologi Perairan}

Aspek ekologi perairan yang diteliti meliputi karakteristik perairan, sifat fisika-kimiawi air, plankton dan makrofita. Pengambilan contoh air dan plankton dilakukan dengan metode pengambilan contoh strata (Nielsen \& Johnson, 1985). Perairan yang diperiksa dibagi secara horizontal dalam tiga stratum (stasiun) dan secara vertikal dalam dua stratum (lapisan permukaan air dan $20 \mathrm{~cm}$ di atas dasar perairan) yang diharapkan mewakili seluruh perairan. Jenis dan kelimpahan relatif makrofita diamati di seluruh perairan demikian pula habitat pemijahan (spawning ground) dan asuhan (nursery ground) ikannya

\section{Penelitian Populasi Ikan}

Populasi ikan yang meliputi struktur komunitas ikan, pakan alami dan kebiasaan makan serta reproduksi diteliti dari sampel ikan yang ditangkap dengan menggunakan jaring insang ukuran mata jaring 1,0;
$1,5,2,0,2,5$, dan 3,0 inci. Sampel ikan juga dikumpulkan dari hasil tangkapan nelayan di perairan sekitar suaka. Struktur komunitas ikan dipelajari dengan mencatat jenis ikan yang tertangkap dan proporsi kelimpahannya. Pakan dan kebiasaan makan ikan dianalisis menggunakan metode Hyslop (1980), sedangkan fekunditas (reproduksi) ikan dianalisis dengan metode Bagenal \& Braum (1978). Distribusi dan pola migrasi ikan yang dominan dipelajari melalui penandaan (tagging) ikan menggunakan metode Hayase et al. (1984). Penandaan ikan ini diumumkan kepada nelayan dan masyarakat setempat, sehingga diharapkan ikan bertanda yang tertangkap kembali dilaporkan mengenai nomor tanda, ukuran panjang total ikan, tempat dan waktu tertangkapnya. Jenis ikan dominan yang ditandai adalah sepat siam (Trichogaster pectoralis), puyau (Osteochilus hasselti), biawan (Helostoma temminckii), baung (Mystus nemurus), dan pepuyu (Anabas testudineus). Jumlah dan kisaran panjang total ikan yang ditandai tertera pada Tabel 1

\section{Penilaian Fungsi dan Efektivitas Suaka}

Penilaian fungsi dan efektivitas suaka dilakukan dengan menganalisis beberapa parameter ekologis perairan dan populasi ikan berdasarkan nilai skor 
seperti tertera pada Tabel 2. Berdasarkan total skor yang dinilai dari parameter ekologis perairan dan populasi ikannya, suaka perikanan yang diteliti dikelompokkan atas (1) suaka yang berfungsi rendah dan kurang atau tidak efektif, (2) suaka yang berfungsi sedang dan cukup efektif, dan (3) suaka yang berfungsi baik dan sangat efektif.

Tabel 1. Jumlah dan panjang total ikan yang ditandai di suaka Batu Bumbun Table 1. Number and total length of fish species tagged at Batu Bumbun reserve

\begin{tabular}{lccc}
\hline \multicolumn{1}{c}{$\begin{array}{c}\text { Jenis ikan } \\
\text { Fish species }\end{array}$} & N & $\begin{array}{c}\text { Panjang Total/Total Length (cm) } \\
\text { Kisaran/range }\end{array}$ & Rataan/Average \\
\hline Pepuyu, A. testudineus & 1098 & $10.0-18.0$ & 15.5 \\
Biawan, H. temminckii & 939 & $9.0-18.0$ & 12.5 \\
Sepat Siam, $T$. pectroralis & 251 & $11.0-17.0$ & 14.5 \\
Baung, $M$. nemurus & 298 & $12.0-31.0$ & 21.0 \\
Puyau, O. hasselti & 34 & $10.0-17.0$ & 13.0 \\
\hline
\end{tabular}

Tabel 2. Nilai skor untuk menilai fungsi dan efektivitas suaka Danau Batu Bumbun Table 2. Scoring value for measuring the effectiveness of Batu Bumbun reserve

\begin{tabular}{|c|c|c|c|}
\hline \multirow{2}{*}{ Parameter } & \multicolumn{3}{|c|}{ Nilai Skor/Scoring value } \\
\hline & 1 & 2 & 3 \\
\hline \multicolumn{4}{|c|}{ Ekologis perairan(Aquatic ecology) } \\
\hline $\begin{array}{c}\text { Luas perairan } \\
\text { Water surface area }\end{array}$ & $<200$ ha & $>200-500$ ha & $>500$ ha \\
\hline $\begin{array}{l}\text { Rata-rata kedalaman air } \\
\text { Av. of water depth }\end{array}$ & $<2 \mathrm{~m}$ & $>2-15 m$ & $>15-25 m$ \\
\hline $\begin{array}{c}\text { Kualitas air } \\
\text { Water quality }\end{array}$ & buruk/bad & sedang/medium & baik/good \\
\hline $\begin{array}{l}\text { Kelimpahan plankton } \\
\text { Macrophyte density }\end{array}$ & $0-2,000 \mathrm{ind} / \mathrm{L}$ & $2,000-15000 \mathrm{ind} / \mathrm{I}$ & $>15,000 \mathrm{ind} / \mathrm{l}$ \\
\hline $\begin{array}{l}\text { Tempat asuhan ikan } \\
\text { Nursery ground }\end{array}$ & $<1 \%->25 \%$ area & $>1-10 \%$ area & $>10->25 \%$ area \\
\hline $\begin{array}{l}\text { Tempat pemijahan } \\
\text { Spawning ground }\end{array}$ & tidak ada/non & terbatas//imitted & tersedia/favourable \\
\hline $\begin{array}{r}\text { Populasi ikan (Fish population) } \\
\text { Keanekaragaman spesies }\end{array}$ & & & \\
\hline Species diversity & $\mathrm{kecil} / \mathrm{small}$ & sedang/medium & tinggi/high \\
\hline $\begin{array}{l}\text { Kelimpahan stok } \\
\text { Stock density }\end{array}$ & $\mathrm{kecil} / \mathrm{small}$ & sedang/medium & tinggi/high \\
\hline $\begin{array}{l}\text { Spesies langka } \\
\text { Endanger species }\end{array}$ & tidak ada/non & 1 spesies/species & $>1$ spesies/species \\
\hline
\end{tabular}

\section{HASIL DAN BAHASAN}

\section{Ekologi Perairan}

Danau Batu Bumbun mempunyai luas permukaan air 450 ha dengan kedalaman antara 1-4 m. Perairan danau dikelilingi oleh hutan rawang dan airnya berhubungan dengan Sungai Mahakam melalui dua 
Tabel 3. Parameter ekologis perairan Danau Batu Bumbun

Table 3. Aquatic ecological parameters of Batu Bumbun lake

\begin{tabular}{|c|c|c|}
\hline Parameter & $\begin{array}{l}\text { Nilai Kisaran } \\
\text { Range Value }\end{array}$ & $\begin{array}{l}\text { Krite ria Optimum } \\
\text { Optimum Criteria }\end{array}$ \\
\hline $\begin{array}{l}\text { Luas permukaan air (ha) } \\
\text { Water surface area (ha) }\end{array}$ & $200-450$ & - \\
\hline $\begin{array}{l}\text { Kedalaman air }(\mathrm{m}) \\
\text { Water depth }(m)\end{array}$ & $1.0-4.0$ & - \\
\hline $\begin{array}{l}\text { Kecerahan }(\mathrm{cm}) \\
\text { Transparency }(\mathrm{cm})\end{array}$ & $30-55$ & $30-60$ (Boyd, 1990) \\
\hline $\begin{array}{l}\text { Suhu air }\left({ }^{\circ} \mathrm{C}\right) \\
\text { Water Temparature }\end{array}$ & $29.0-30.6$ & $25.0-32.0$ (Boyd, 1990) \\
\hline $\begin{array}{l}\text { Konduktivitas }(\mathrm{mohm} / \mathrm{cm}) \\
\text { Conductivity }(\mathrm{mohm} / \mathrm{cm})\end{array}$ & $160-185$ & $150-500$ (Brower \& Zar, 1984) \\
\hline $\begin{array}{l}\text { Oksigen terlarut }(\mathrm{mg} / \mathrm{L}) \\
\text { Dissolved Oxygen }(m g / L)\end{array}$ & $3.0-6.4$ & $3.0-7.3($ Boyd, 1990) \\
\hline $\mathrm{pH}$ (unit) & $4.0-6.8$ & $6.5-8.5$ (Boyd, 1990) \\
\hline $\begin{array}{l}\text { Total padatan terlarut }(\mathrm{mg} / \mathrm{L}) \\
\text { Total dissolved solids }(\mathrm{mg} / \mathrm{L})\end{array}$ & $75.6-90.8$ & $1-400$ (Meade, 1990) \\
\hline $\begin{array}{l}\text { Alakalinitas (mg/L } \mathrm{CaCO}_{3} \text { eq.) } \\
\text { Alkalinity }\left(\mathrm{mg} / \mathrm{L} \mathrm{CaCO}_{3} \text { eq.) }\right.\end{array}$ & $55-72$ & $20-300$ (Meade, 1989) \\
\hline
\end{tabular}

Keterangan/Legend:

Data diambil dari 7 kali sampling di 3 stasiun pengamatan (Data recorded from 7 times sampling at 3 stations)

saluran penghubung. Oleh karena itu, fluktuasi air Danau Batu Bumbun sangat dipengaruhi oleh pasang surutnya Sungai Mahakam. Pada musim kemarau saluran penghubung dan bagian pinggir danau kering sehingga luas permukaan airnya menyusut menjadi sekitar 200 ha.

Kisaran nilai parameter kunci kualitas air Danau Batu Bumbun tertera pada Tabel 3. Kualitas air biasanya menurun secara ekstrim pada musim kemarau sampai permulaan musim hujan. Pada permulaan musim hujan antara Desember sampai Januari, perairan di sekitar Danau Batu Bumbun biasanya berwarna hitam, berbau busuk, bersifat asam $(\mathrm{pH}=4,5)$ dengan kandungan oksigen antara $0,5-1,5 \mathrm{mg} / \mathrm{L}$. Peristiwa ini oleh masyarakat setempat disebut "air bangar" dan biasanya diikuti dengan kematian ikan secara massal. Namun demikian, Danau Batu Bumbun biasanya terhindar dari peristiwa air bangai tersebut. Kandungan oksigen terlarut di danau masih berkisar antara 3,0-6,4 mg/L dan $\mathrm{pH}$ berkisar antara 4,0-6,8. Kondisi perairan danau tersebut masih layak untuk kehidupan jenis-jenis ikan rawa (black fish) di mana jenis ikan tersebut tidak pernah berruaya jauh. Sedangkan jenis-jenis ikan putihan (white fish) yang berruaya lebih jauh biasanya menghindari kondisi kualitas perairan yang menurun tersebut ke perairan sungai utama (Mahakam) yang mempunyai kualitas air yang lebih baik.

Jenis fitoplankton di Danau Batu Bumbun didominasi oleh Diatoma, Lyngbya, dan Ulothrix. Sedangkan zooplankton didominasi oleh Cyclopoida dan Rotifera (Tabel 4). Berdasarkan kelimpahan planktonnya, Danau Batu Bumbun termasuk perairan dengan kesuburan sedang. Namun demikian kelimpahan plankton terutama fitoplankton di perairan ini diduga akan tinggi jika tidak terjadi persaingan pertumbuhan dengan makrofita yang kelimpahannya cukup tinggi.

Makrofita (tumbuhan air) di Danau Batu Bumbun terdiri dari eceng gondok (Eichhornia crassipes), rumput kumpai (Panicum spp; Paspalum spp), kayu duri (Mimosa nigra), kiambang (Salvinia sp), ganggeng (Hydrilla verticillata, Myriophylum sp., Utricularia spp.), kangkung (Ipomoea aquatica), rumput bakau (Polygonum sp.), dan teratai (Nymphaea sp). Makrofita ini didominasi oleh rumput kumpai (35\%), kayu duri $(20 \%)$ dan eceng gondok (15\%). Dewasa ini, perkembangan makrofita yang pesat telah menutupi hampir $60 \%$ luas perairan atau meningkat dari $40 \%$ pada tahun sebelumnya seperti yang 


\begin{tabular}{ccc}
$\begin{array}{l}\text { Tabel 4. } \\
\text { Table 4. }\end{array}$ & $\begin{array}{c}\text { Kelimpahan plankton (individu/L) di Danau Batu Bumbun } \\
\text { Density of plankton (individua//L) at Batu Bumbun }\end{array}$ \\
\hline Plankton & Permukaan (Surface) & Kedalaman 2 m (2m Depth) \\
\hline Phytoplankton : & & $30-45$ \\
Anabaena & $40-55$ & $115-130$ \\
Lyngbya & $135-160$ & $40-80$ \\
Mougeotia & $70-85$ & $30-65$ \\
Oscillatoria & $45-70$ & $95-135$ \\
Ulothrix & $120-150$ & $45-70$ \\
Navicula & $65-95$ & $15-35$ \\
Pinnularia & $25-55$ & $145-190$ \\
Diatoma & $170-210$ & $165-180$ \\
Zooplankton : & & $30-65$ \\
Cyclopoida & $165-190$ & $130-160$ \\
Cladocera & $40-70$ & \\
Rotifera & $145-175$ &
\end{tabular}

Keterangan/Legend:

Data diambil dari 7 kali sampling di 3 stasiun/Data recorded from 7 times sampling at 3 sampling stations

dilaporkan Sarnita (1994). Perkembangan makrofita ini perlu dikendalikan sehingga populasinya tidak lebih 25\% dari total luas perairan (Pandit, 1984) karena jika terus dibiarkan maka fungsi suaka akan berkurang

\section{Populasi Ikan}

Jenis ikan yang terdapat di Suaka Batu Bumbun terdiri atas 18 jenis (Tabel 5) yang didominasi oleh pepuyu, sepat siam, biawan dan kendia. Keanekaragaman jenis ikan di suaka ini termasuk relatif sedang dan sekitar $10 \%$ dari jenis ikan yang ditemukan di DAS Mahakam yakni 147 spesies (Christensen, 1992). Jenis ikan umumnya terdiri atas jenis-jenis ikan rawa. Hal ini juga mencerminkan bahwa kondisi habitat perairan Danau Batu Bumbun lebih mendekati perairan rawa.

Struktur komunitas ikan didominasi oleh ikan non predator $70 \%$ dan sisanya adalah ikan predator. Menurut Odum (1971) perbandingan yang baik antara populasi ikan predator (carnivorous fish) dan ikan nonpredator (forage fish) adalah 1:4. Dengan demikian, struktur komunitas ikan di perairan ini dapat dikatakan berada dalam keadaan seimbang. Percobaan penangkapan di Danau Batu Bumbun dengan menggunakan jaring insang ( gillinet) pada waktu air surut memperoleh Jejawis ikan yaitu sepat siam, tempe, puyau, dan kendian pepun buawan, sepat siam, dan pepuyu yang tertangkap umumnya dalam keadaan matang gonad. Hal ini menandakan bahwa suaka tersebut merupakan tempat pemijahan dan waktu pemijahannya diduga terjadi pada permulaan air sungai naik

Dugaan waktu pemijahan ini didukung dengan hasil pengamatan pada bulan Maret 1995 saat banyak ditemukan benih ikan kendia, pepuyu, dan biawan dengan ukuran panjang antara 1-2 cm. Benih tersebut bergerombol dekat tumbuhan air di pinggir danau. Benih dengan ukuran tersebut diperkirakan merupakan hasil pemijahan sebulan yang lalu atau sekitar bulan Januari-Februari. Berdasarkan fekunditas dari jenis ikan tersebut, setiap induk biawan, sepat siam, pepuyu, puyau, dan kendia masing-masing diperkirakan mempunyai potensi reproduksi sebesar $8.000,6.000,5.500,18.000$, dan 5.400 butir telur (Tabel 6). Satria et al. (1994) melaporkan bahwa ikan kendia dari Danau Semayang dan Melintang mempunyai potensi reproduksi sebesar 4.200-5.800 butir telur.

Pada musim kemarau saat perairan suaka surut, beberapa jenis ikan yakni sepat siam dan biawan banyak yang terserang penyakit borok-borok dan banyak di antara jenis ikan tersebut mati. Kondisi ini diduga karena pada waktu itu kualitas perairan menurun sedangkan populasi ikan berada dalam kelimpahan yang tinggi. 
Tabel 5. Jenis-jenis ikan yang ditemukan di Danau Batu Bumbun

Table 5. Fish species found at Batu Bumbun lake

\begin{tabular}{llc}
\hline \multicolumn{1}{c}{$\begin{array}{c}\text { Nama Lokal } \\
\text { Local Name }\end{array}$} & \multicolumn{1}{c}{$\begin{array}{c}\text { Nama Ilmiah } \\
\text { Scientific Name }\end{array}$} & $\begin{array}{c}\text { Kelimpahan Relatif } \\
\text { Relatif density }\end{array}$ \\
\hline Berukung & $\begin{array}{l}\text { Barbichthys laevi } \\
\text { Biawan }\end{array}$ & + \\
Emplostoma temminckii & +++ \\
Haruan & Macrochirichthys macrochirus $\left.{ }^{*}\right)$ & + \\
Jelawat & ${\left.\text { Channa striatus }{ }^{*}\right)}^{\text {Leptobarbus hoeveni }}$ & ++ \\
Kalibere & Mystus nigriceps * & ++ \\
Baung & Mystus nemurus $\left.{ }^{*}\right)$ & + \\
Kendia & Thynichthys vaillanti & ++ \\
Puyau & Osteochilus hasselti & +++ \\
Kelabau & Osteochilus waandersi & + \\
Pepuyu & Anabas testudineus & + \\
Sepat siam & Trichogaster pectoralis & +++ \\
Sepat rawa & Trichogaster trichopterus & +++ \\
Tempe & Peristolepis fasciatus & ++ \\
Tebal dada & Cyclocheilichthys repasson & ++ \\
Repang & Puntius nini & + \\
Lalang & Chela oxygastroides & ++ \\
Betutu & Oxyeleotris marmorata * & ++ \\
\hline
\end{tabular}

$+=$ jarang $(<25 \%$ total tangkapan $) /$ rare $(<25 \%$ of total catch);

$++=$ sedang $(25-50 \%$ total tangkapan)/ moderate (26-50\% of total catch)

$+++=$ banyak $(>50 \%$ total tangkapan $) /$ many $(>50 \%$ of total catch)

$\left.{ }^{*}\right)=$ predator (carnivorous)

Tabel6. Kebiasaan makan dan fekunditas 5 jenis ikan yang dominan di suaka Batu Bumbun

Table 6. Food habits and fecundity of 5 dominant fish species at Batu Bumbun reserve

\begin{tabular}{llc}
\hline Jenis Ikan (Fish Species) & Kebiasaan Makan (Food Habits) & Fekunditas (Fecundity) \\
\hline Sepat siam, T. pectoralis & Planktivor-insectivor & $5.400-8.800$ \\
Biawan, H. temminckii & Planktivor & $6.500-9.200$ \\
Pepuyu, A. testudineus & Insectivor & $4.500-7.200$ \\
Puyau, O. hasselti & Periphyton-detritivor & $12.400-25.400$ \\
Kendia, T. vailanti & Planktivor & $5.200-6.800$ \\
\hline
\end{tabular}

Frekuensi distribusi panjang total ikan yang ditandai terlihat pada Gambar 3. Berdasarkan distribusi panjang totalnya terlihat bahwa ikan sepat, biawan, dan pepuyu masih menunjukkan sebaran ukuran populasi yang normal. Sedangkan populasi ikan baung dan puyau berada pada distribusi ukuran yang relatif kecil-kecil. Hal ini menandakan bahwa populasi ikan sepat, biawan, dan pepuyu masih baik 

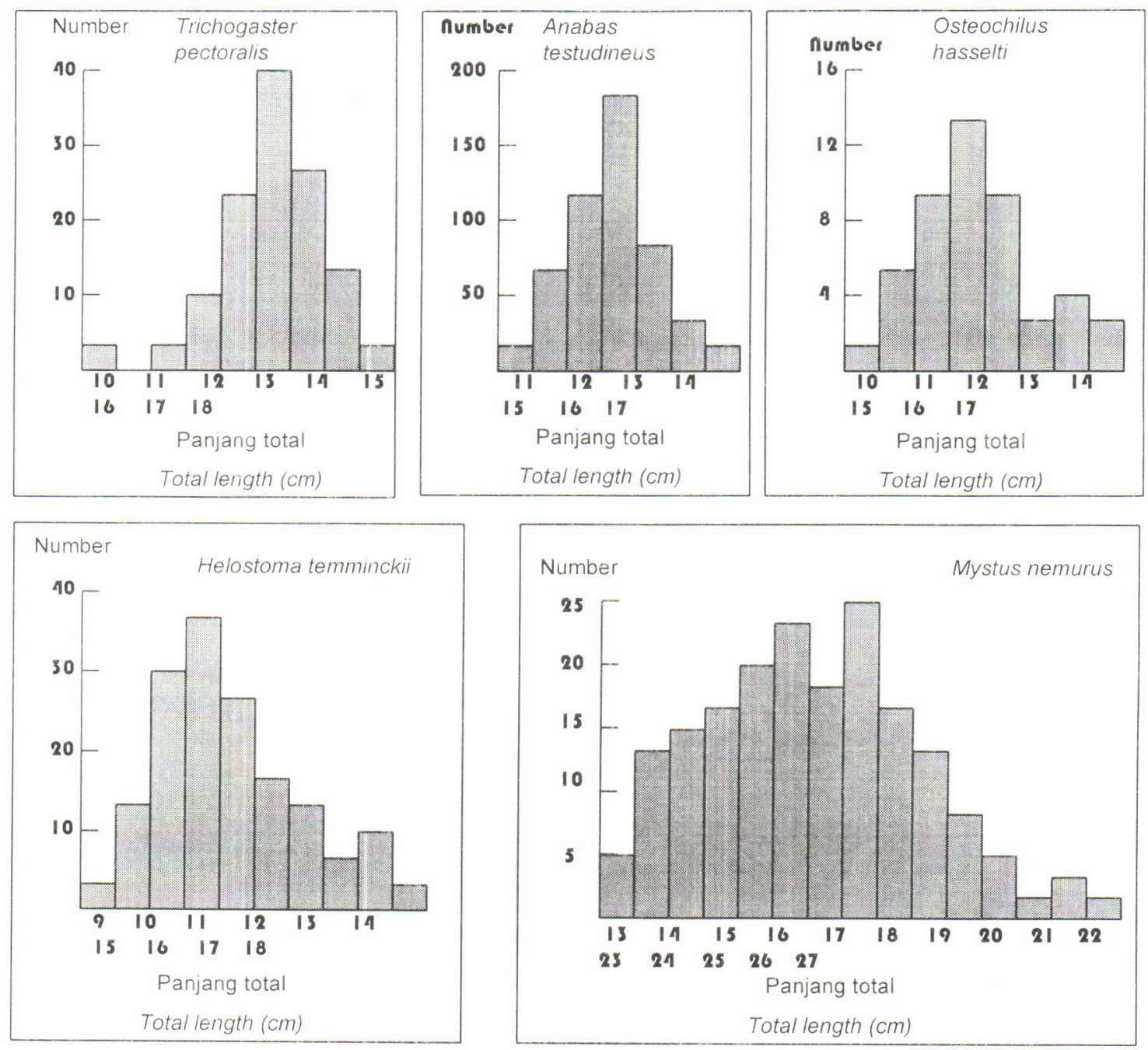

Gambar 3. Distribusi frekuensi panjang total ikan yang ditandai di Suaka Batu Bumbun

Figure 3. Length frequency distribution of fish species tagged at Batu Bumbun reserve

sedangkan populasi ikan baung dan puyau sudah mulai menurun.

Jumlah ikan bertanda yang dilaporkan tertangkap kembali hanya berkisar antara 2-5\% dari total ikan yang ditebarkan. Ikan pepuyu, biawan, dan sepat siam yang tertangkap masih berada di sekitar daerah penebaran dengan jarak sekitar $1 \mathrm{~km}$ ke arah hilir dari daerah penebaran. Ikan baung bermigrasi cukup jauh yakni ke arah hulu Sungai Mahakam, kurang lebih $2 \mathrm{~km}$ dari tempat penebaran (Gambar 4). Hal ini diperkirakan berhubungan erat dengan kondisi kualitas air. Pada permulaan bulan Januari saat kualitas perairan sekitar danau menurun sebagai akibat terjadinya air bangai telah memicu ikan untuk bermigrasi ke daerah dengan kualitas air baik yaitu di daerah batang Sungai Mahakam.

Percobaan penangkapan di suaka hanya mendapatkan ikan pepuyu, sepat siam, dan biawan yang bertanda sedangkan ikan baung, dan puyau tidak pernah didapat. Hal ini menandakan bahwa ikan pepuyu, sepat siam dan biawan bermigrasi dari sungai ke suaka dan suaka tersebut merupakan habitat yang sesuai untuk kehidupannya.

\section{Fungsi dan Efektivitas Suaka}

Suaka perikanan pada prinsipnya berfungsi sebagai wilayah perairan untuk menghasilkan benih ikan secara alami sehingga rekrutmen populasi ikan di perairan sekitarnya meningkat. Berdasarkan penilaian beberapa parameter ekologis perairan dan populasi ikannya seperti yang telah ditetapkan pada Tabel 2 , didapatkan jumlah nilai skor 22. Dengan demikian, Danau Batu Bumbun sebagai suaka perikanan ternyata tergolong suaka yang berfungsi sedang dan cukup efektif sebagai pemasok benih ikan dan penyediaan stok induk ikan (Tabel 7) terutama untuk ikan-ikan rawa.

Jenis ikan yang dominan di suaka tersebut adalah ikan biawan, pepuyu, kendia, dan puyau. Ikan dominan yang tertangkap pada umumnya dalam keadaan 




Gambar 4. Pola ruaya ikan yang ditandai di Suaka Batu Bumbun

Figure 4. Migration pattern of fish species tagged at Batu Bumbun reserve

matang gonad. Pada waktu air tinggi di bagian pinggir suaka banyak ditemukan benih ikan. Benih ikan yang dihasilkan secara alami ini dapat ditingkatkan melalui penebaran ulang (restocking) dengan induk ikan yang benar-benar dapat mengadakan pemijahan di suaka tersebut. Penebaran ulang terutama perlu dilakukan setelah terjadinya peristiwa air bangai karena pada waktu itu beberapa jenis ikan mati dan sebahagian lagi bermigrasi kearah sungai yang mempunyai kualitas air lebih baik. Untuk lebih meningkatkan fungsi suaka tersebut maka perbaikan (rehabilitasi) habitat agar lebih sesuai dengan kebutuhan hidup ikan, baik kebutuhan sebagai daerah pemijahan maupun pengasuhan perlu dilakukan. Tumbuhan air perlu dikendalikan sehingga populasinya tidak melebihi dari $25 \%$ luas perairan sedangkan penebangan hutan rawang perlu dihentikan karena habitat ini penting bagi tempat pemijahan dan pembesaran anak-anak ikan. Habitat tersebut sangat penting peranannya dalam peningkatan populasi ikan. Sebagai contoh perbaikan habitat yang dilakukan di Sungai Severn, Inggris, ternyata berdampak positif terhadap peningkatan stok ikan "dace" dan "chub" masing-masing sebesar 75\% dan 35\% (Swales \& O'Hara, 1983).

\section{Implikasi Pengelolaan Suaka}

Pengelolaan suaka perikanan adalah berbagai upaya atau tindakan yang ditujukan untuk menjaga dan meningkatkan fungsi dan efektivitas suaka. Tindakan pengelolaan yang perlu dilakukan pada hakekatnya ditujukan untuk mencegah terjadinya penurunan populasi ikan sehingga populasi tersebut dapat pulih kembali dan sekaligus melestarikannya. Beberapa tindakan pengelolaan yang perlu dilakukan meliputi kegiatan sebagai berikut:

a. Pengelolaan Habitat: Pengelolaan habitat meliputi kegiatan pengendalian tumbuhan air sehingga 
Tabel 7. Nilai skor fungsi dan efektifitas suaka Danau Batu Bumbun

Table 7. Scoring value of function and efectivitness of Batu Bumbun reserve

\begin{tabular}{|c|c|c|}
\hline $\begin{array}{l}\text { Parameter } \\
\text { Parameters }\end{array}$ & $\begin{array}{l}\text { Nilai Nyata } \\
\text { Actual value }\end{array}$ & $\begin{array}{l}\text { Nilai Skor sesuai Tabel } 2 . \\
\text { Scoring value based on table } 2\end{array}$ \\
\hline \multicolumn{3}{|c|}{ Ekologis perairan (Aquatic ecology) } \\
\hline $\begin{array}{l}\text { Luas perairan } \\
\text { Water surface area }\end{array}$ & $200-450$ ha & 2 \\
\hline $\begin{array}{l}\text { Rata-rata kedalaman air } \\
\text { Av. of water depth }\end{array}$ & $2 \mathrm{~m}$ & 2 \\
\hline $\begin{array}{l}\text { Kualitas air } \\
\text { Water quality }\end{array}$ & sedang/medium & 2 \\
\hline $\begin{array}{l}\text { Kelimpahan plankton } \\
\text { Macrophyte density }\end{array}$ & sedang/medium & 2 \\
\hline $\begin{array}{l}\text { Tempat asuhan ikan } \\
\text { Nursery ground }\end{array}$ & $60 \%$ area & 1 \\
\hline $\begin{array}{l}\text { Tempat pemijahan } \\
\text { Spawning ground }\end{array}$ & tersedia/favourable & 3 \\
\hline \multicolumn{3}{|l|}{ Populasi ikan (Fish population) } \\
\hline $\begin{array}{l}\text { Keanekaragaman spesies } \\
\text { Species diversity }\end{array}$ & sedang/medium & 2 \\
\hline $\begin{array}{l}\text { Kelimpahan stok } \\
\text { Stock density }\end{array}$ & Tinggi/high & 3 \\
\hline $\begin{array}{l}\text { Spesies langka } \\
\text { Endanger species }\end{array}$ & 1 spesies/species & 2 \\
\hline Total skor (Total scoring) & & 22 \\
\hline
\end{tabular}

Total skor/total scoring: $<15=$ berfungsi rendah dan kurang efektif/low function and less effective

16-25 = berfungsi sedang dan cukup efektif/medium function and sufficiently effective $>25$ = berfungsi baik dan sangat efektif/good function and very effective

populasinya tidak melebihi $25 \%$ luas perairan, penambahan "snag structure", manipulasi tempat pemijahan termasuk menjaga penebangan pohon sebagai hutan rawang dan menghentikan perubahan habitat lainnya yang merupakan penyebab utama menurunnya populasi ikan. Keterbatasan dana pengelolaan untuk pengendalian tumbuhan air nampaknya akan menjadi kendala. Alternatif terbaik yang dapat ditempuh adalah jika dana tersebut dapat dipikul secara bersama oleh nelayan sekitarnya dengan cara menyisihkan sebagian hasil tangkapannya sehingga fungsi dan efektivitas suaka meningkat. Pengerukan saluran penghubung antara suaka dengan Sungai Mahakam perlu dilakukan sehingga pada musim kemarau saluran tersebut masih tetap berair dan berhubungan dengan Sungai Mahakam. Pengkayaan makanan alami, misalnya dengan penebaran atau introduksi jenis zooplankton seperti Daphnia sp. yang telah berhasil diintroduksikan di Waduk Jatiluhur. Tindakan lain yang perlu dilakukan adalah perluasan dan peningkatan perlindungan koridor migrasi, tempat pemijahan dan tempat asuhan dan pembesaran anak-anak ikan. Dengan demikian, perlindungan tidak hanya daerah perairannya saja tetapi juga perlu meluas ke daerah daratan serta vegetasi sekitarnya. Daerah suaka perlu diperluas meliputi anak Sungai Mahakam dengan jarak antara $1 \mathrm{~km}$ ke arah hilir dan hulu dari saluran pemasukan air ke danau tersebut.

b. Pengelolaan Populasi Ikan: Dalam pengelolaan populasi ikan yang perlu dilakukan adalah menjaga keseimbangan antara ikan pemangsa dan mangsa, penebaran atau penebaran ulang (restocking) dengan jenis ikan yang dapat melakukan reproduksi seperti biawan, pepuyu, puyau, dan kendia. Penebaran ikan tersebut terutama dilakukan setelah terjadi peristiwa air bangai sebagai pengganti induk-induk ikan yang mengalami kematian.

c. Pengembangan Pengawasan, Peraturan dan Kelembagaan: Upaya yang perlu dilakukan adalah 
patroli dan pengawasan serta penerapan sanksi yang tegas terhadap penangkap ikan di daerah suaka. Pemasangan rambu-rambu larangan secara jelas yang disertai uraian singkat mengenai sanksi pelanggaran juga perlu dilakukan. Pengembangan kelembagaan pengelolaan dapat dilakukan dengan cara melibatkan secara aktif masyarakat setempat dalam pengelolaan suaka (community based management). Pembentukan dan pembinaan kelompok nelayan sebagai pengawas suaka secara aktif akan meningkatkan keamanan perlindungan daerah suaka tersebut.

d. Sosialisasi Suaka: Upaya penanaman pengertian dan penyuluhan akan fungsi, peranan, dan pentingnya suaka perlu terus dilakukan. Tindakan pengelolaan yang diperkirakan akan merupakan hambatan dan kendala adalah sosialisasi suaka ataupun pengembangan kelembagaan karena masih terbatasnya tenaga petugas dan penyuluh perikanan yang menguasai permasalahan suaka

\section{KESIMPULAN DAN SARAN}

Dari hasil penelitian ini dapat disimpulkan dan disarankan hal-hal sebagai berikut :

1. Berdasarkan aspek ekologi perairan dan populasi ikannya, Danau Batu Bumbun masih berfungsi sedang dan cukup efektif sebagai suaka terutama untuk jenis-jenis ikan rawa. Oleh sebab itu, perlu dilakukan peningkatan dalam pengelolaannya. Peningkatan produksi benih alami di suaka ini dapat dilakukan dengan cara penebaran ulang (restocking) ikan pepuyu, biawan, puyau, dan sepat siam yang kemudian diikuti dengan upaya rehabilitasi habitatnya terutama pengendalian makrofita dan pengerukan saluran penghubung antara suaka dengan Sungai Mahakam

2. Perbaikan pengelolaan suaka hendaknya meliputi pengelolaan habitat, pengelolaan populasi ikan, pengembangan pengawasan secara aktif, pengembangan pengelolaan oleh masyarakat (community-based management) dan sosialisasi suaka.

3. Dinamika populasi jenis-jenis ikan dominan baik yang terdapat di suaka maupun di daerah penangkapan sekitarnya perlu dilakukan sehingga parameter populasinya dapat diketahui.

\section{DAFTAR PUSTAKA}

Anonim. 1991. Pengelolaan Reservat dan Restocking di Perairan Umum. Petunjuk Pelaksanaan. Dit. Sumber Hayati, Ditjen Perikanan, Departemen Pertanian. Jakarta. 35pp
Bagenal, T.B. and Erich Braum. 1978. Eggs and early life history. In T.B. Bagenal (ed.) Methods Assessment of Fish Production in Freshwaters. 3rd ed. IBP Hand Book No.3, Blackwell Sci. Pub., Oxford,. P:165-202

Boyd, C.E. 1990. Water Quality in Pond for Aquaculture. Alabama Agricultural Experiment Station. Auburn University, Auburn, Alabama. 482pp.

Brower, J.E. and J.H. Zar. 1984. Field and Laboratory Methods for General Ecology. 2nd ed. Wm C. Brown Pub. Dubuque, lowa. 276p.

Christensen, M.S. 1992. Investigation on the ecology and Fish Fauna of the Mahakam River in East Kalimantan (Borneo), Indonesia. Int. Revuges. Hydrobiol., 77(4): 593-608

Hayase, S., D. Somjaiwong and S. Chullasorn. 1984 Manual on Tagging of Marine Animals. Special Pub. No. 10. Training Department. SEAFDEC. Thailand. $38 \mathrm{pp}$.

Hyslop, E.J. 1980. Stomach contents analysis-a review of methods and their application. J.Fish.Biol., 17:411429

Kottelat, M., A.J. Whitten, S.N. Kartikasari and S. Wirjoatmodjo. 1993. Freshwater fishes of Western Indonesia and Sulawesi (Ikan air tawar Indonesia Bagian Barat dan Sulawesi). Periplus Editions Ltd. Indonesia. 293p.

Meade, J.W. 1989. Aquaculture Management. An AVI Book, Van Nostrand Reinhold, New York. 174p.

Nielsen, L.A. and D.L. Johnson. 1985. Fisheries techniques. Am. Fish. Soc. Bethesda, Maryland. $468 p p$.

Odum, E.P. 1971. Fundamentals of Ecology, 3rd ed. W.B. Saunders Co., Tokyo, Japan. 326pp.

Pandit, A.K. 1984. Role of macrophytes in aquatic ecosystems and management of freshwater resources. Journal of Environmental Management (18): 73-88.

Purnomo, K. 1993. Potensi sumberdaya perikanan di Danau Semayang dan Melintang. Frontir-Universitas Mulawarman No. 14, Edisi September 1993. Samarinda. p.123-136

Sarnita, A.S. 1994. Penelitian teknologi reservat sumber daya perikanan di DAS Musi dan Mahakam. Laporan Proyek Lingkungan Hidup Perikanan. Puslitbang Perikanan, Jakarta. $21 \mathrm{pp}$

Satria, H; K. Purnomo dan Ristono. 1994. Penelitian biologi reproduksi beberapa jenis ikan di Danau Semayang, Melintang dan Jempang. FrontirUniversitas Mulawarman No.15, Edisi Pebruari 1994. Samarinda. p.12-23.

Swales, S. and K. O'Hara. 1983. A short-term study of the effects of a habitat improvement programme on the distribution and abundance of fish stocks in a small lowland river in Shropshire. Fish. Mgmt. 14 (3):135-144 